\title{
BOICOTE DE CONSUMIDORES EM RELAÇÃO À RESPONSABILIDADE SOCIAL CORPORATIVA: PROPOSIÇÕES A PARTIR DO CONTEXTO BRASILEIRO
}

\author{
Breno de Paula Andrade Cruz \\ Doutor em Administração pela EAESP/FGV \\ Professor da Universidade Federal Rural do Rio de Janeiro \\ brenocruz@ufrrj.br
}

\section{RESUMO}

A problemática da Responsabilidade Social Corporativa (RSC) tem permeado o cotidiano empresarial nos últimos anos e as orientações teóricas sobre esse conceito divergem de acordo com a área de conhecimento e o interesse do autor. A teoria que norteia o conceito de RSC neste artigo é a dos Stakeholders, que propõe a gestão dos interesses de todos os atores ligados, direta ou indiretamente, a uma empresa (Freeman, 1984); Freeman e Velamuri, 2006). O consumidor é um destes stakeholders e também pode ter seus interesses satisfeitos ou não. Este artigo foi o primeiro trabalho no Brasil a estudar a relação do boicote dos consumidores com a Responsabilidade Social Corporativa. O boicote é um comportamento de repúdio que se caracteriza pela decisão do consumidor em deixar de comprar um produto, serviço ou uma marca (Friedman, 1999; Klein, Smith e John, 2004), o que pode gerar perdas tangíveis de ordem econômica. Este trabalho exploratório se torna relevante por algumas características, tais como: (a) identificar uma lacuna no contexto brasileiro sobre o comportamento do consumidor e a relação com RSC; (b) demarcar o conceito de boicote de consumidores, diferenciando do conceito de Backlash; e, (c) instigar pesquisadores a trabalhar as proposições apresentadas neste estudo em futuras pesquisas. Como principal resultado deste trabalho exploratório, são apresentadas nove proposições que vão desde a relação com variáveis de mercado (mercado monopolista) até influência de terceiros, por exemplo. Estas proposições podem ser trabalhadas tanto na perspectiva qualitativa quanto na quantitativa e são relacionadas à Responsabilidade Social Corporativa.

Palavras-chave: Boicotes; Comportamento do consumidor; Responsabilidade social corporativa; Teoria dos stakeholders.

\section{CONSUMER'S BOYCOTT IN CORPORATE SOCIAL RESPONSIBILITY: PROPOSITIONS BASED ON THE BRAZILIAN CONTEXT.}

\section{ABSTRACT}

Corporate Social Responsibility (CSR) has been permeating the business context in the last few years and the theoretical perspectives addressing this concept diverge according to the knowledge area and the author's background. The theory that gives basis to the CSR concept in this paper is the Stakeholders' Theory, which suggests the administration of the Stakeholders' interests (Freeman, 1984; Freeman \&Velamuri, 2006). Consumers are considered to be one of these stakeholders and they can have their interests fulfilled or not. This paper was the first study in Brazil which investigated the relationship between consumers' boycott and CSR, taking into account a business perspective. The boycott is a repudiated behavior, which is characterized by the consumer's decision of not buying a product, service, or brand (Friedman, 1999; Klein, Smith \&John, 2004), possibly leading to financial loss for the company. This is an exploratory study and is relevant because of some characteristics, such as: a) identifying a gap between the consumer's behavior and CSR in the Brazilian context; b) outlining the consumer's boycott context, differentiating it from the concept of Backlash; and, c) encouraging researchers to use the propositions presented in this paper for future studies. As the main outcome of this investigation, nine propositions are presented that range from market economic structure to influence of others. These propositions can be investigated not only using qualitative, but also quantitative data and are related to CSR.

Key words: Behavior consumer; Boycotts; Corporate social responsibility; Stakeholders' theory.

Revista de Gestão Social e Ambiental - RGSA, São Paulo, v. 7, n. 1, p. 19-34, jan./abr. 2013. 


\section{INTRODUÇÃO}

Alguns temas como Responsabilidade Social Corporativa (RSC) e Sustentabilidade têm recebido grande destaque na agenda de grandes, pequenas e médias empresas e também nos periódicos nacionais. Seja numa perspectiva pragmática ou numa perspectiva crítica, esta problemática tem perpassado o cotidiano de empresas que buscam uma melhor posição no mercado ou uma (re)construção de uma cultura organizacional que priorize valores, tais como respeito e atendimento aos interesses dos Stakeholders, respeito ao meio ambiente e à sociedade, e, também, a geração de valor ao acionista.

Nesta lógica sistêmica e que analisa não somente os interesses econômicos da empresa é que o conceito de Responsabilidade Social Corporativa (RSC) é abordado neste artigo, ou seja, não se tem a preocupação de abordar o tema somente na lógica do retorno financeiro para os acionistas, e, são considerados, também, outros atores envolvidos, como funcionários e clientes. Uma empresa socialmente responsável atende aos interesses dos atores envolvidos direta ou indiretamente em seus processos - e um desses atores é o consumidor. De acordo com a Teoria dos Stakeholders, o sucesso de uma empresa dependerá de como ela gerencia os interesses dos diversos atores (Donaldson e Preston, 1995).

Considerando que o consumidor é um destes Stakeholders e é normal que seus interesses sejam atendidos por uma empresa, pode ser racional pensar que o não atendimento destes interesses pode gerar prejuízos financeiros para as empresas. Quando um valor ou um conjunto de valores de um grupo de consumidores não estão congruentes ou distantes dos valores organizacionais ou mercantilistas de uma empresa, seus produtos ou serviços podem não ser comprados por este grupo. Numa ação ativista, este grupo de consumidores (sendo influenciados ou não por outros grupos ou instituições) pode deixar de comprar um produto, um serviço ou uma marca de uma empresa.

A situação em que os valores pessoais do consumidor não correspondem aos valores organizacionais de uma empresa e que gera um comportamento de repúdio deste com relação a práticas de responsabilidade social, resultando em possíveis prejuízos tangíveis e intangíveis a uma marca, é chamada de Backlash (Smith et al, 2010, p. 622). Já o boicote é uma forma de backlash, sendo mais específico, uma vez que o comportamento de repúdio se caracteriza com a decisão do consumidor em deixar de comprar um produto, serviço ou uma marca (Klein, Smith e John, 2004), podendo gerar perdas tangíveis de ordem econômica.

Os valores sociais e mercantilistas da atual sociedade têm mudado ao longo das últimas décadas. Seja pelo aumento da entrada de cidadãos em universidades ou pela facilidade de comunicação por meio da Internet, o fato é que o cidadão hoje tem uma melhor percepção de danos que uma empresa pode causar à sociedade, ao meio ambiente, aos seus funcionários e a outros possíveis atores. Mas será que o consumidor brasileiro está propenso a participar de boicotes?

O que se percebe é que as empresas, cada vez mais, se preocupam com sua imagem e sua reputação organizacional, como evidencia Aaker (2004) ao apresentar resultados de perdas financeiras de empresas que tiveram suas reputações ou imagens negativadas em razão de acidentes ambientais ou posturas ideológicas da empresa. A imagem está relacionada à percepção de um grupo de pessoas (físicas ou jurídicas, com valores semelhantes) sobre uma organização. Já a reputação é conceituada como o conjunto das imagens de uma empresa (Argenti, 2005), ou seja, as percepções dos grupos com relação a uma determinada empresa. Tanto uma quanto a outra se torna um ativo intangível na lógica competitiva em vigor.

O boicote de um consumidor a uma empresa, produto ou serviço, além de gerar o prejuízo financeiro tangível, que reflete no resultado contábil da companhia em um determinado período, gera também o prejuízo financeiro intangível. Assim como no prejuízo financeiro tangível, o prejuízo financeiro intangível ocorre por meio da negativação da imagem ou reputação da empresa com relação à sua atuação diante de seus stakeholders. Um exemplo dessa perda sobre a imagem ou reputação foi a empresa petrolífera americana Shell que não aderiu ao Protocolo de Kyoto e perdeu

Revista de Gestão Social e Ambiental - RGSA, São Paulo, v. 7, n. 1, p. 19-34, jan./abr. 2013. 
7\% de participação no mercado, sendo atribuída essa perda ao boicote dos consumidores (Aaker, 2004). No Brasil, a empresa calçadista Arezzo teve que retirar a coleção 'Pele Mania' de todas as lojas no país após manifestações de consumidores e ativistas na rede social virtual Facebook (Cruz, 2011).

É perceptível que “(...) marcas que efetivamente transportam um significado e valores estão mais vulneráveis ao ativismo de mercado" (Smith et al, 2010, p. 626) - como foi o caso da empresa de material e acessórios esportivos Nike ao negligenciar em sua cadeia de suprimentos empresas terceirizadas na China que se utilizavam de mão de obra semiescrava. Quanto mais reconhecida for uma marca, maior será o impacto negativo que um boicote causará à sua reputação.

Este artigo, que tem sua característica exploratória ao fazer uma revisão de literatura sobre o boicote dos consumidores, objetiva realizar uma pesquisa bibliográfica tendo como base os conceitos de boicote e backlash e busca entendê-los na perspectiva da Responsabilidade Social Corporativa, apresentando proposições e gerando insights para futuras pesquisas na área de comportamento do consumidor no Brasil. Esta primeira parte problematizou o tema boicote e sua relação com a Responsabilidade Social Corporativa. O item seguinte faz uma revisão de literatura dos temas aqui apresentados, discutindo: (i) RSC e suas abordagens teóricas; (ii) a relação do comportamento do consumidor e RSC; e, (iii) o boicote do consumidor e sua diferença em relação ao backlash. Por fim, o último item do texto apresenta proposições e sugestões para futuras pesquisas.

\section{REVISÃO DE LITERATURA}

A revisão de literatura deste artigo está dividida basicamente em três partes. A primeira, apresenta o conceito de RSC e suas quatro correntes teóricas e suas respectivas abordagens. A segunda, discute o comportamento do consumidor com relação às práticas de RSC adotadas por empresas e como isso pode impactar nas atitudes dos consumidores em relação a tais posturas. Já o terceiro item desta revisão de literatura aborda a questão do Backlash e do Boicote, fazendo a demarcação dos conceitos e os possíveis resultados para as empresas a partir desta postura dos consumidores ou organizações formadoras de opinião.

\subsection{Responsabilidade Social Corporativa}

Por ser um tema transversal que perpassa diversas áreas de conhecimento, desde a Filosofia, por meio do entendimento da Ética, até a Administração, na busca de melhores retornos tangíveis e intangíveis (imagem e reputação), a RSC tem recebido, nos últimos anos, uma atenção especial no contexto empresarial mundial. Entretanto, o viés adotado para abordagem RSC depende da orientação que o autor busca para abordar o tema e Dahlsrud (2008) analisou 37 definições sobre RSC em seu estudo - o que, de fato, demonstra a transversalidade do tema.

Por exemplo, os teóricos que têm maior preocupação com o retorno financeiro farão uma análise do tema como uma estratégia que permite à empresa desempenhos financeiros superiores (Auperlle, Carroll e Hatfield, 1985). Outros autores se preocupam com a análise da RSC como uma orientação gerencial, seja na perspectiva de responder às demandas do mercado (Bhattacharya et al, 2008; Wood, 1991) ou na perspectiva holística de entender os atores que compõem o processo de gestão da RSC (Cruz, 2009; Ashley, 2005; Donaldson e Preston, 1995). Já um autor crítico, tenderá a analisar RSC em uma perspectiva em que serão considerados principalmente o funcionário, a sociedade e o meio ambiente, deixando de problematizar stakeholders como acionistas e executivos (Tenório, 2004). Já os pesquisadores da área de Marketing tenderão escolher uma abordagem de questões relacionadas à aceitação do produto ou de uma marca no mercado e, em seguida, associála à imagem da empresa (Nan e Heo, 2007; Currás-Perez et al, 2009). É neste último viés que este artigo se fundamenta, sem deixar de levar em consideração a ideia de que a RSC deve ser pautada em uma orientação gerencial. A figura 1, a seguir, apresenta os principais enfoques na problematização de RSC.

Revista de Gestão Social e Ambiental - RGSA, São Paulo, v. 7, n. 1, p. 19-34, jan./abr. 2013. 


\begin{tabular}{|c|c|c|}
\hline Autor(es) & Viés Teórico & Ideia Central \\
\hline \begin{tabular}{|c|} 
Auperlle, Carroll e \\
Hatfield (1985)
\end{tabular} & Rentabilidade & Considerar RSC como estratégia para aumentar os lucros. \\
\hline \begin{tabular}{|c|} 
Bhattacharya et al \\
(2008)
\end{tabular} & \multirow[b]{2}{*}{ Responsivo } & $\begin{array}{c}\text { Resgata a dinâmica dos relacionamentos entre a sociedade e a } \\
\text { empresa. }\end{array}$ \\
\hline Wood (1991) & & \begin{tabular}{|c|} 
A orientação estratégia da empresa é construída com base na \\
percepção interna e externa e da responsabilidade do negócio em \\
resposta às demandas da sociedade
\end{tabular} \\
\hline Cruz (2009) & \multirow{3}{*}{ Gerencial-Holístico } & $\begin{array}{c}\text { Orientação gerencial que a empresa adota com o objetivo de } \\
\text { atender os interesses de todos os stakeholders, não se limitando a } \\
\text { ações filantrópicas. }\end{array}$ \\
\hline $\begin{array}{c}\text { Donaldson e Preston } \\
(1995)\end{array}$ & & $\begin{array}{c}\text { A empresa deve gerenciar os interesses individuais de seus } \\
\text { atores buscando encontrar uma situação ótima em que todos } \\
\text { sejam beneficiados }\end{array}$ \\
\hline Ashley (2005) & & $\begin{array}{c}\text { A empresa valoriza os funcionários e os direitos dos acionistas, } \\
\text { além de manter boa relação com clientes, fornecedores, } \\
\text { sociedade e meio ambiente. }\end{array}$ \\
\hline Tenório (2004) & Social-crítico & $\begin{array}{c}\text { Promover a gestão social, também internamente, como forma de } \\
\text { ser socialmente responsável. }\end{array}$ \\
\hline Nan e Heo (2007) & Estratégico-Promocional & $\begin{array}{c}\text { RSC como ações filantrópicas ou caridosas de ajuda a ONGs } \\
\text { que trabalham com causas sociais em prol de uma boa reputação } \\
\text { corporativa. }\end{array}$ \\
\hline $\begin{array}{c}\text { Currás-Pérez et al } \\
\text { (2009) }\end{array}$ & Comportamento do Consumidor & $\begin{array}{c}\text { RSC como uma variável importante para o consumidor analisar } \\
\text { o comportamento de uma empresa e decidir sobre comprar ou } \\
\text { não um produto ou serviço. }\end{array}$ \\
\hline
\end{tabular}

Figura 1 - Posicionamentos teóricos na Responsabilidade Social Corporativa

Fonte: $\mathrm{O}$ autor

Muitas das práticas de empresas que contratam serviços de consultoria na área de RSC estão alicerçadas na última corrente da RSC - que é denominada Cidadania Corporativa. Nesta, conforme poderá ser visto posteriormente, a empresa já cumpriu com suas obrigações internas, externas e com os demais stakeholders, e, assim, poderá se engajar em causas filantrópicas ou caridosas que promovam o bem-estar humano (Carrol, 1991 apud Melé, 2008, p. 68). Entretanto, o que se vê, muitas vezes, são empresas tentando sua autopromoção por meio de ações filantrópicas ou caridosas.

O handbook de Responsabilidade Social Corporativa, lançado pela Oxford University em 2008 (Crane et al, 2008), reúne textos importantes que definem desde questões epistemológicas da área até questões práticas e perspectivas futuras de estudos na área de RSC. É baseado no terceiro capítulo deste livro[i] que são encontradas as correntes teóricas que ao longo dos últimos anos ajudam a explicar o comportamento de empresas no Brasil e em outros países. As seções seguintes apresentam as abordagens para RSC.

\subsubsection{Desempenho social corporativo}

A primeira das quatro teorias que compõe o que hoje se caracteriza como Responsabilidade Social Corporativa é apresentada com um viés do retorno que algumas práticas podem gerar a uma determinada empresa. Entretanto, esta teoria não tem como objetivo a busca pela rentabilidade econômica das atividades estruturadas. Embora semelhante no que diz respeito às ações, a principal diferença para a Teoria dos Acionistas é que os princípios da ação socialmente responsável são construídos a partir de uma orientação organizacional que considera políticas, programas e resultados tangíveis na relação com a sociedade (Wood, 1991).

De acordo com o autor supracitado, o Desempenho Social Corporativo é construído com base em três princípios: (i) princípios gerais - que consideram a legitimidade do negócio perante a 
sociedade e a responsabilidade da empresa com a sociedade; (ii) Responsividade da empresa - dar resposta aos interesses a um ator interno ou externo; e, (iii) Resultados do Comportamento Corporativo - estudos que analisam o impacto social (positivo ou negativo) da ação da empresa. Em conjunto com a Teoria dos Stakeholders, esta primeira teoria dá a base teórica para o que hoje se discute sobre RSC.

\subsubsection{Teoria dos acionistas}

Esta teoria, diferentemente das demais, tem como foco o acionista. Embora o foco fosse aumentar a lucratividade dos acionistas, isso aconteceria por meio de ações socialmente corretas. Assim, a Teoria do Valor ao Acionista é definida por Melé (2008) como um conjunto de ações sociais de um negócio que busca incrementar os lucros de uma empresa para os acionistas, além de aumentar o seu valor de mercado. Para esta corrente teórica, a partir do momento que ações com foco social são planejadas e implementadas, pode-se gerar valor ao acionista. Para isso, é necessário destacar que o executivo é diretamente responsável pelos seus colaboradores e também por atender aos interesses dos proprietários ou acionistas. Entretanto, não se pode afirmar que sempre a implementação de práticas sociais resultará em benefícios aos acionistas.

Para Melé (2008), a partir de uma análise crítica, a Teoria do Valor ao Acionista fica mais clara quando se analisa, na perspectiva das possíveis perdas econômicas, que impactos sociais negativos podem causar a uma empresa. Um clima organizacional inadequado, problemas relacionados à qualidade de vida no trabalho ou situações internas que resultam em problemas sociais externos (por exemplo, meio ambiente) podem gerar perdas para a empresa. Resumidamente, o desempenho econômico pode ser afetado por questões sociais, e, por isso, os gestores passaram a se preocupar com estas questões. Numa análise mais crítica, bem mais parece uma estratégia de apagar incêndio.

\subsubsection{Teoria dos Stakeholders}

O termo stakeholder não tem tradução em Português. Entretanto, entende-se o termo como um ator (uma organização ou um conjunto de pessoas físicas) que mantém diretamente ou indiretamente uma relação com uma empresa[ii]. Este termo foi usado pela primeira vez em 1963 em uma reunião de departamento do Stanford Research Institute (Melé, 2008). De acordo Donaldson e Preston (1995, p.81), o termo stakeholder tem como objetivo evidenciar as relações existentes entre a empresa e outros atores. Neste contexto, o sucesso da empresa dependerá de como o gerenciamento dos interesses destes stakeholders será conduzido e como isso poderá afetar a organização. Ou seja, a empresa gerencia os interesses individuais de seus atores buscando encontrar uma situação ótima em que todos sejam beneficiados.

Assim, o sucesso de uma firma pode depender que como ela gerencia os interesses de um stakeholder. Cruz (2009) apresenta alguns stakeholders que podem ser considerados no contexto brasileiro, tais como funcionários, acionistas, fornecedores, sociedade e meio ambiente, governo (municipal, estadual e federal), ONGs, comunidades vizinhas a uma empresa, parceiros estratégicos (empresas ou instituições), milícias e organizações ilegais, associações de bairro, escolas e grupos religiosos.

Conforme aponta Melé (2008), é sensato pensar que alguns interesses de alguns stakeholders são mais importantes do que os interesses de outros. Por isso, é uma habilidade gerenciar tais interesses. Uma das grandes vantagens desta teoria é que ela não separa a Ética dos Negócios - não é uma teoria da Ética desconectada da Gestão (Ashley, 2005). Uma vez que a empresa entende os interesses das partes, ela age de acordo com os princípios éticos, pois respeita algumas das partes (sociedade, meio ambiente e colaboradores).

\subsubsection{Cidadania corporativa}

Revista de Gestão Social e Ambiental - RGSA, São Paulo, v. 7, n. 1, p. 19-34, jan./abr. 2013. 
A última corrente teórica sobre Responsabilidade Social Corporativa está relacionada à Filantropia. Entende-se aqui que a empresa se engaja em atividades sociais internas ou externas. De acordo com Birch (2001) apud Melé (2008, p. 69), é necessário não confundir Cidadania Corporativa com Responsabilidade Social Corporativa. Esta última está preocupada com as responsabilidades sociais da empresa e o relacionamento externo, sendo que a Cidadania Corporativa entende a empresa como uma parte da sociedade, e, portanto, deve estar envolvida em atividades sociais. A empresa atua no desenvolvimento educacional de um grupo ou envolve questões relacionadas à saúde e proteção ao meio ambiente, por exemplo. Em outras palavras,

Cidadania Corporativa pode ser conceituada a partir da ação da empresa em gerar contribuições para a sociedade através de atividades que estejam associadas ao seu core business, seus investimentos sociais e programas filantrópicos (Melé, 2008, p. 70) Tradução livre do autor.

De acordo com os autores que contribuem para a construção desta corrente teórica, uma empresa que atua na perspectiva da Cidadania Corporativa não pode se preocupar somente em atender às questões mínimas da legislação social ou ambiental. Para Gardberg e Fombrun (2006), uma empresa que atua na perspectiva da Cidadania Corporativa vai além das obrigações mínimas, como, por exemplo, o voluntarismo corporativo, as contribuições caridosas, os programas ambientais, educacionais e profissionais. Ou seja, para as empresas chegarem neste estágio de envolvimento com a sociedade, elas devem atender anteriormente os desejos de todos os stakeholders envolvidos. Por exemplo, não se pode pensar em ajudar uma comunidade carente e contratar na cadeia de suprimentos um fornecedor com trabalho semiescravo. Parece que esta perspectiva de ação, semelhante à conhecida expressão em Administração "apagar incêndio", norteia algumas empresas que pretendem ter RSC como estratégia competitiva e não como orientação gerencial.

\subsection{Comportamento do consumidor e Responsabilidade Social}

As transformações ocorridas no contexto cultural, social e econômico nas últimas três décadas têm influenciado consideravelmente as estratégias competitivas tanto de pequenas quanto de médias e grandes empresas. No caso das empresas multinacionais, este fenômeno talvez seja mais presente pelo fato de estas terem que entender características específicas de um país ou continente para uma atuação mais focada e eficiente.

Os valores e anseios dos consumidores também mudaram consideravelmente nas últimas décadas, motivados também pela tecnologia e pela interatividade dos internautas entre eles mesmos ou com empresas - não é raro, por exemplo, uma grande empresa possuir um perfil no Facebook ou no Twitter (Cruz, 2013). Assim, a avalanche de informações disponíveis em websites de organizações não-governamentais, na mídia ou em sites de relacionamento contribui na facilidade dos consumidores compararem seus próprios valores de vida com os valores da marca que oferece um produto ou serviço.

Conforme destaca Smith et al. 2010, a tecnologia ajuda na expansão da empresa e em um contato mais próximo com um consumidor que esteja geograficamente mais distante, e, ao mesmo tempo, prejudica pelo fato de acelerar o fluxo de informações (em alguns casos prejudiciais à empresa) que podem denegrir a reputação de uma marca.

Para os pesquisadores da área de Marketing e até mesmo para os gerentes de empresas, entende-se hoje que a compra de um produto ou serviço agrega atributos que vão além das necessidades que aquele produto ou serviço possa suprir ao consumidor, indo ao encontro do estilo de vida deste consumidor (Palazzo e Basu, 2007). Ou seja, o processo de escolha envolve também atributos intangíveis, ou, não conscientes - conforme destacam Fitzsimons et al (2002).

Para estes últimos autores, o processo de escolha não-consciente do consumidor envolve, na primeira dimensão, a questão da polarização do julgamento. Assim, o julgamento de escolha de

Revista de Gestão Social e Ambiental - RGSA, São Paulo, v. 7, n. 1, p. 19-34, jan./abr. 2013. 
uma marca, produto ou serviço é realizada, inicialmente, por uma dicotomia que pode ser expressa pelo 'Sim versus Não', pelo 'Ter versus Não Ter' ou também 'Ser versus Não Ser'. Ou seja, o julgamento atende essa forma dicotômica que está em um dos polos analisados pelo consumidor.

No caso da RSC, a dicotomia 'ser' ou 'não ser' socialmente responsável tem influenciado o comportamento das empresas pelo medo que elas sentem quanto a possibilidade de o consumidor deixar de comprar produtos ou serviços por não alinharem seus valores pessoais com práticas divulgadas na mídia ou por organizações não-governamentais que defendem alguns grupos desfavorecidos. Por exemplo, a partir de um comentário do CEO da empresa Phillips com relação ao estado do Piauí, em que Paulo Zotollo diz que "se o Piauí deixar de existir ninguém vai ficar chateado", uma grande rede de eletrônicos do Piauí deixou de comprar e comercializar produtos da Phillips (Agência da Folha, 2007).

Embora numa visão limitada do conceito de RSC em que os autores analisaram tal conceito como ações filantrópicas ou apoio de empresas a ONGs ou fundações que trabalhavam com causas sociais, Nan e Heo (2007) verificaram que os consumidores acreditam que empresas que fazem tais ações são socialmente responsáveis, e, como resposta a essa postura, os consumidores avaliam positivamente a intenção de compra de um produto ou serviço da empresa que realizou ações filantrópicas.

Ainda na lógica da publicidade e da propaganda, Matilla et al. (2010) analisaram como que a inserção de mensagens socialmente responsáveis em campanhas de instituições de serviços financeiros poderiam influenciar os consumidores em uma atitude positiva de compra em relação à marca. Considerando a questão da religiosidade e dos valores, Ramasamy et al. (2010) concluíram, em um estudo realizado em Singapura e Hong Kong, que a religião influencia pessoas religiosas a comprar um produto ou serviço e a pagar a mais por isso se o consumidor religioso percebe o engajamento de uma empresa na atuação socialmente responsável.

Buscando evidenciar a identificação do consumidor com uma empresa, Currás-Pérez et al. (2009) construíram um modelo de equações estruturais para validar algumas hipóteses relacionadas com a imagem socialmente responsável de uma empresa e sua relação de efeito na atratividade da marca, e, consequentemente, como a atratividade da marca influenciaria a identificação do consumidor com a empresa na intenção de compra. Após uma vasta revisão de literatura, os autores definiram os construtos, que são apresentados na figura 2.

\begin{tabular}{|c|c|c|}
\hline Variável & Definição & Autores utilizados[iii] \\
\hline $\begin{array}{c}\text { Identificação do } \\
\text { consumidor com a } \\
\text { empresa }\end{array}$ & $\begin{array}{c}\hat{E} \text { um estado cognitivo de autocategorização, conexão e } \\
\text { proximidade do consumidor com a empresa }\end{array}$ & $\begin{array}{c}\text { Bergami e Bagozzi (2000); } \\
\text { Bhattacharya e Sen (2003) }\end{array}$ \\
\hline $\begin{array}{c}\text { Imagem socialmente } \\
\text { responsável }\end{array}$ & $\begin{array}{c}\text { Um poderoso canal para expressar a personalidade da } \\
\text { empresa para os consumidores }\end{array}$ & Balmer (2001) \\
\hline $\begin{array}{c}\text { Coerência da marca } \\
\text { Prestígio da marca }\end{array}$ & $\begin{array}{c}\text { Características da marca (ou valores da empresa) que ajudam } \\
\text { a explicar aos Stakeholders quem a empresa realmente é }\end{array}$ & Bhattacharya e Sen (2003 \\
\hline $\begin{array}{c}\text { Originalidade da } \\
\text { marca }\end{array}$ & $\begin{array}{c}\text { É a comparação de uma marca com outra buscando } \\
\text { evidenciar características singulares da primeira em relação à } \\
\text { segunda }\end{array}$ & Fombrum e Shanley (1990) \\
\hline $\begin{array}{c}\text { Atratividade da } \\
\text { marca }\end{array}$ & $\begin{array}{c}\text { Uma avaliação positiva da identidade da empresa que } \\
\text { examina e calcula como uma marca pode satisfazer seus } \\
\text { consumidores em suas próprias necessidades }\end{array}$ & Bhattacharya e Sen (2003); \\
Dutton et al. (1994)
\end{tabular}

Figura 2 - Definição das variáveis analisadas por Currás-Pérez et al (2009) na construção do modelo teórico de identificação do consumidor com a empresa.

Revista de Gestão Social e Ambiental - RGSA, São Paulo, v. 7, n. 1, p. 19-34, jan./abr. 2013. 
Fonte: Construído pelo autor a partir de Currás-Pérez et al. (2009).

A partir da apresentação das variáveis, os autores apresentaram graficamente o modelo de equações estruturais que foi validado empiricamente. A Figura 3 apresenta o modelo e o resultado da análise empírica obtida pelos autores a partir de consumidores espanhóis. Conforme pode ser analisado na figura, a imagem socialmente responsável que a empresa comunica aos consumidores tem influência positiva no prestígio e na originalidade da marca, o que evidencia, neste último caso, que a comparação entre marcas ou empresas, no que diz respeito à responsabilidade social, realmente tem impacto na percepção do consumidor com relação a atratividade da marca, que, por sua vez, afetará a intenção de consumo. Isso ajuda na análise que o construto 'Identificação do Consumidor com a Empresa' recebe e influência indiretamente na imagem socialmente responsável que a empresa comunica aos seus consumidores.

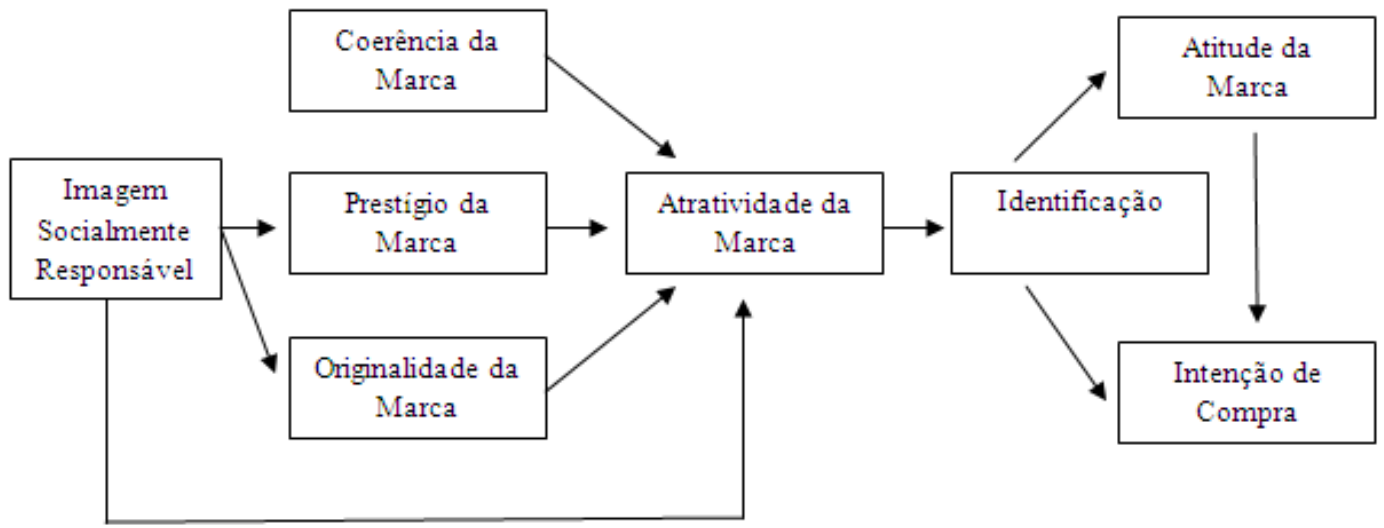

Figura 3 - Identificação do consumidor com uma empresa socialmente responsável Fonte: Adaptado a partir de Currás-Pérez et al (2009, p. 551)

A percepção do consumidor sobre uma empresa pode ser considerada também a partir do ramo de atuação e dos seus valores. Por exemplo, uma empresa com viés mais capitalista (instituição financeira) pode não ser considerada socialmente responsável quando comparada com uma empresa de telecomunicações. Matilla et al. (2010) analisaram justamente estas duas empresas e a primeira conclusão dos autores foi que a instituição financeira possuía uma avaliação geral de sua atuação inferior à empresa de telefonia. Levando-se em consideração os valores pessoais, é possível que algum grupo de consumidores não esteja favorável a associar seus valores pessoais aos valores capitalistas de uma instituição financeira hipotecária, mas não se pode inferir que isso sempre acontecerá.

Desta maneira, numa perspectiva estratégica, percebe-se empiricamente, no contexto analisado por Cúrras-Pérez et al. (2009), que RSC é um atributo que distingue uma empresa da outra na análise do consumidor na intenção e na atitude de compra. Ou seja, uma postura socialmente responsável torna uma marca mais atrativa ao consumidor se ele comunga daqueles valores, o que contribui também para que sua escolha seja coerente com seus valores. Da mesma forma, supõe-se que isso possa ocorrer também no boicote - conforme apresentado a seguir.

\subsection{Backlash, Boicote e Responsabilidade Social Corporativa}

Conforme indicam Nan e Heo (2007), uma marca será forte se os seus valores são similares aos valores de causas sociais. Numa validação empírica conduzida pelos autores em um grupo de consumidores da universidade de Midwestern nos Estados Unidos, a veiculação de mensagens direcionadas aos consumidores de uma marca influenciou, positivamente, quando analisadas separadamente (técnica de experimento) a atitude positiva de compra daqueles consumidores. 
Entretanto, qual a reação dos consumidores quando estes recebem mensagens negativas do comportamento de uma empresa?

O medo de sofrer boicote dos consumidores por parte de grandes empresas é explicado a partir de casos de grandes marcas como Nike, Coca Cola e Shell. No caso da Nike, por exemplo, que envolveu o escândalo da utilização de mão de obra infantil na China em sua cadeia de suprimentos, o boicote dos consumidores, com apoio de uma ONG, fez com que o CEO da empresa recebesse mais de 33 mil cartas solicitando mudanças nas condições de trabalho na cadeia de suprimentos da empresa (Palazzo; Basu, 2007). Este exemplo evidencia que a decisão de consumo pode afetar as práticas laborais (Smith et al., 2010) de uma empresa ou de sua cadeia de suprimentos.

Por pressão de boicote de universidades americanas e canadenses, a Coca-Cola teve que rever sua atuação na Colômbia no que diz respeito à violação de direitos humanos, uma vez que os contratos e produtos da Coca-Cola foram banidos de 20 universidades naqueles dois países (Kreyre, 2006 apud Palazzo e Basu, p. 338-339), pelo fato de as universidades não concordarem com as práticas adotadas pela empresa. Já a Shell perdeu entre 10 e 15 milhões de dólares por dia no ano de 1999 pelo fato de os consumidores terem boicotado a empresa pelo famoso caso Brent Spar (Knight e Pretty, 2000). O Green Peace apurou também que a Shell perdeu 7\% de participação de mercado depois de não aderir ao Protocolo de Kyoto (Aaker, 2004).

Embora esta transformação ideológica nos valores dos consumidores permeie a lógica da competição no mercado, o que se percebe é que esta estratégia gerencial muda de acordo com os valores presentes em cada país ou continente. Por exemplo, conforme destacam Maignan e Ralston (2002) em uma pesquisa realizada nos Estados Unidos e na Europa, empresas americanas em seus discursos sobre RSC se preocupam muito mais com os valores que norteiam suas ações do que as empresas europeias. De acordo com a pesquisa, as empresas europeias, principalmente aquelas presentes na Holanda e na França, tendem a adotar práticas de RSC em razão da pressão dos stakeholders e não pelos seus próprios valores organizacionais.

Conforme visto anteriormente na Teoria dos Stakeholders, o sucesso de uma empresa dependerá de como ela conseguirá gerenciar os interesses dos seus stakeholders. Assim, levando em consideração somente um dos stakeholders - os consumidores, o sucesso de uma marca dependerá dos valores que reafirmam sua identidade e que os diferenciam de outros grupos (Smith et al, 2010) ou da coerência dos seus valores pessoais com os valores sociais e ambientais de uma marca. Uma marca forte será aquela que consegue amarrar, de maneira eficiente, fortes emoções com os valores dos clientes (Aaker, 2004).

A situação em que os valores pessoais do consumidor não correspondem aos valores organizacionais de uma empresa e que gera um comportamento de repúdio deste com relação às práticas de RSC, resultando em possíveis prejuízos tangíveis e intangíveis a uma marca, é chamado de Backlash (Smith et al, 2010, p. 622). Este termo, sem tradução literal, transmite a ideia de que os valores dos consumidores ou outros grupos se chocam com os valores da empresa e o retorno que se tem é negativo para a corporação que sofre com tal ação. Assim, consequentemente, essa incoerência da marca na comunicação de seus valores reduz sua atratividade ao consumidor (Curras-Perez et al, 2009), gerando perdas para a companhia.

Embora Backlash e boicote possam ser entendidos como sinônimos no inglês, neste artigo apresenta-se um viés epistemológico semântico diferente e entende-se que o boicote é um tipo de Backlash, pois este último acaba sendo mais amplo que o boicote. De acordo com o Longman Dictionary of Contemporany English (2009), o termo Backlash, na perspectiva sociológica, diz respeito a uma "[...] reação negativa de uma coletividade a uma ideia ou produto a partir de uma reflexão e não é somente ignorar algo, vai além ao propor uma rejeição [...]" que geralmente é abrupta. Já o boicote está relacionado ao ato de deixar de comprar algum produto (Klein, Smith e John, 2004; Friedman, 1999; Soule, 2009; Cruz, 2013). O exemplo na figura abaixo pode ajudar a clarificar tal diferença. 


\section{Situação}

Uma empresa do ramo esportivo contrata um novo jogador para compor o elenco do time para a nova temporada. A torcida se irrita com a contratação, pois o novo jogador fez gestos obscenos para aquela torcida dois anos atrás, quando era de um time rival e ganhou o campeonato estadual naquela ocasião.

Backlash $\square$ os torcedores se reúnem e rejeitam a atitude da empresa da nova contratação. Fazem manifestos na sede do clube solicitando o cancelamento do contrato.

Boicote $\square$ os torcedores não compram as camisas e os objetos do clube com o nome do novo jogador e deixam de ir (temporariamente) às partidas, o que resulta na diminuição das receitas para o clube.

Figura 4 - Diferença entre Backlash e Boicote

Fonte: Elaborado pelo autor.

Nesta lógica, um boicote é uma forma de Backlash, uma vez que consumidores deixam de comprar um produto ou serviço, se caracterizando uma forma intrigante de comportamento do consumidor (Klein, Smith e John, 2004). A literatura no Brasil já aborda alguns casos de boicote. O estudo exploratório de Cruz (2011) apresentou casos de boicote de consumidores ocorridos nos últimos anos (Figura 5). Outros estudos abordaram o boicote à empresa Arezzo (Cruz, 2012) por meio das redes sociais virtuais; a influência de pessoas famosas no boicote, via redes sociais virtuais (Cruz et al, 2012) e a análise da sensação de culpa do consumidor em relação a um bem de luxo como (Cruz e Ross, 2013).

\begin{tabular}{|c|c|c|}
\hline Caso & Situação & Desdobramentos \\
\hline Phillips & $\begin{array}{l}\text { Presidente da Phillips diz que se o Piauí } \\
\text { deixasse de existir ninguém ficaria chateado. }\end{array}$ & $\begin{array}{l}\text { O Grupo Claudino, grande rede varejista do } \\
\text { Piauí, deixou de comprar produtos Phillps. }\end{array}$ \\
\hline Pão de Queijo & $\begin{array}{l}\text { Lanchonete de tradicional escola paulistana } \\
\text { aumenta em } 25 \% \text { o preço do pão de queijo }\end{array}$ & $\begin{array}{l}\text { Alunos se mobilizam, deixam de comprar, } \\
\text { postam vídeos no Twitter e Youtube e o assunto } \\
\text { passa a ser discutido na imprensa brasileira. }\end{array}$ \\
\hline $\begin{array}{l}\text { Rede Globo } \\
\text { Copa } 2010\end{array}$ & $\begin{array}{l}\text { Usuários do Twitter propuseram que o jogo } \\
\text { entre Brasil e Portugal na Copa de } 2010 \text { não } \\
\text { fosse visto na rede Globo, pois suas empresas } \\
\text { pediram uma punição ao técnico da seleção } \\
\text { brasileira à FIFA }\end{array}$ & $\begin{array}{l}\text { No Twitter, um dia antes do jogo Brasil e } \\
\text { Portugal, os comentários postados para que os } \\
\text { usuários não vissem o jogo na rede Globo } \\
\text { (\#diasemglobo) entraram para a lista de tópico } \\
\text { mais comentado no país. }\end{array}$ \\
\hline Lula - o filme & $\begin{array}{l}\text { O sindicato das videolocadoras de São Paulo } \\
\text { (2011) diz que Lula fez gestos que incentivam } \\
\text { a pirataria }\end{array}$ & $\begin{array}{l}\text { Sindicato libera carta solicitando que o filme } \\
\text { 'Lula - o filho do Brasil' não seja adquirido } \\
\text { pelas locadoras paulistas. }\end{array}$ \\
\hline
\end{tabular}

Figura 5 - Boicotes no Brasil e seus desdobramentos

Fonte: Elaboração do autor a partir de Cruz (2011).

Embora os jovens do século XXI pareçam ser mais críticos em relação às gerações anteriores, no que diz respeito à intenção de compra levando-se em consideração os comportamentos ambientais e sociais das empresas, não se percebeu muita mudança nas atitudes. Um estudo conduzido pelo Centro de Altos Estudos da ESPM (CAEPM), em parceria com a Universidade Federal do Rio de Janeiro, no final de 2010, nas cidades do Rio de Janeiro e São Paulo, verificou que o jovem brasileiro entre 16 e 25 anos concorda que pode influenciar as ações das empresas, mas, ainda, não consome politicamente. Neste caso, consumir politicamente implica na avaliação dos consumidores sobre as práticas das empresas no que tange seus comportamentos éticos tanto na perspectiva ambiental quanto social (Barbosa, 2010).

Em contrapartida, organizações não-governamentais, governo, mídia ou formadores de opinião deixam de comprar produtos/serviços ou expressam suas ideias como uma forma de 
evidenciar que os valores, comportamentos e as atitudes de uma determinada empresa estão indo em caminho contrário aos seus. Atualmente, Klein, Smith e John (2004, p. 93) consideram que “[...] os motivos dos boicotes estão alicerçados nas práticas das empresas e não com base em motivações sociopolíticas ou nos direitos civis". Isso remete à imagem da empresa no que diz respeito às práticas de responsabilidade social corporativa.

Conforme apontam Palazzo e Richter (2005), a lacuna de credibilidade existente entre a comunicação de Marketing relacionada às ações de RSC e os reais problemas ambientais e sociais que uma empresa está inserida, evidencia o problema da percepção do consumidor com relação à atuação daquela empresa, o que poderá influenciar a decisão destes no momento da compra ou na participação em um boicote.

No que diz respeito à motivação para boicotar um produto, serviço ou marca, Klein, Smith e John (2004) realizaram uma ampla revisão de literatura e apresentam um modelo matemático que analisa os grupos de variáveis que motivam o boicote dos consumidores a um produto ou a uma marca. Os autores dividiram quatro categorias que poderiam influenciar a notoriedade percebida da empresa - primeira hipótese $\left(\mathrm{H}_{1}\right)$; e, a decisão de boicote (sexta hipótese - $\mathrm{H}_{6}$ ) objetivando evidenciar como estas duas variáveis influenciariam a imagem da marca. Estas categorias seriam: (a) fazendo a diferença; (b) autoanálise da situação; (c) argumentos da situação; e (d) resistência em participar do boicote. O quadro a seguir apresenta o objetivo de cada dimensão do modelo.

\begin{tabular}{|c|c|c|}
\hline Dimensão & Objetivo do construto & Variáveis analisadas \\
\hline \multirow{3}{*}{ O consumidor faz a diferença } & \multirow{3}{*}{$\begin{array}{l}\text { O consumidor busca entender quais são } \\
\text { os benefícios do boicote a partir da sua } \\
\text { participação }\end{array}$} & Eficácia do boicote \\
\hline & & Fazer a minha parte \\
\hline & & Mudar o comportamento da empresa \\
\hline \multirow{4}{*}{$\begin{array}{l}\text { Autoanálise do consumidor da } \\
\text { situação de boicote }\end{array}$} & \multirow{4}{*}{$\begin{array}{l}\text { Analisar variáveis psicossociais que } \\
\text { afetam o sentimento de culpa ou bem- } \\
\text { estar do consumidor em relação a ele } \\
\text { mesmo e ao grupo que pertence }\end{array}$} & Culpa \\
\hline & & Desconforto em ser visto por outros \\
\hline & & Pressão familiar ou de amigos \\
\hline & & Sentir melhor \\
\hline \multirow{3}{*}{$\begin{array}{l}\text { Contra-argumentos para não } \\
\text { participar do boicote }\end{array}$} & \multirow{3}{*}{$\begin{array}{l}\text { Analisar quais são os argumentos } \\
\text { contrários à participação, como, não ter } \\
\text { poder de sozinho, mudar a situação ou } \\
\text { transferir a responsabilidade para } \\
\text { terceiros }\end{array}$} & Transferência de responsabilidade \\
\hline & & Ser um pequeno agente \\
\hline & & Consequências do boicote \\
\hline $\begin{array}{l}\text { Constrangimento em deixar de } \\
\text { comprar }\end{array}$ & $\begin{array}{l}\text { Analisar a dificuldade do consumidor em } \\
\text { participar de um boicote. Quanto mais } \\
\text { usar um produto, maior será sua } \\
\text { dificuldade em participar. }\end{array}$ & Histórico de compra \\
\hline
\end{tabular}

Figura 6 - Dimensões e variáveis que motivam um boicote

Fonte: Elaborado pelo autor a partir de Klein, Smith e John (2004).

A partir dessa análise, os autores verificaram que notoriedade da marca, ou seja, quão reconhecida a marca é pelos seus consumidores e demais atores no mercado específico que atua, é um forte indício para que os consumidores participem de um boicote. Assim, quanto maior for a notoriedade da empresa na percepção do consumidor, maior será a possibilidade de ele participar de um boicote. Consequentemente, a decisão de boicotar influencia na imagem da empresa para aquele grupo de consumidores (ou boicotadores).

Klein, Smith e John (2004) verificaram que os quatro construtos têm influência na decisão de boicote. Alguns fatos interessantes são destacados pelos autores, como: (i) a propensão de 
boicotar e o gênero: mulheres estão mais dispostas a boicotar que os homens; (ii) pessoas que acreditam fazer a diferença estarão mais propensas a boicotar se outros já boicotaram; e, (iii) pessoas que usam contra-argumentos para não boicotar, como corte de empregos dos funcionários daquela empresa, não boicotarão se sabem que outros já boicotaram.

Embora Klein, Smith e John (2004) tenham analisado a consciência do consumidor com relação ao seu poder em participar do boicote, os casos que são divulgados na imprensa no Brasil sobre boicotes, na maioria das vezes, envolvem empresas que sabem do seu poder enquanto consumidor de exigir uma postura diferente do seu vendedor. A decisão pelo boicote por parte dos consumidores pode ser estimulada por organizações ou pessoas que considerem abusivas as práticas adotadas por uma determinada empresa (Nan e Heo, 2007). Entretanto, quando se trata de um produto que está inserido num mercado monopolista, como o consumidor pode agir e reagir a um boicote? Por exemplo, quando analisado o segmento petrolífero no Brasil, a Petrobras atua num mercado monopolista.

Como exemplo de atuação monopolista, o Ministério Público do Rio Grande do Norte e os PROCONS do estado lançaram uma campanha, em abril de 2011, para que os consumidores não comprassem combustível nos Postos BR, uma vez que são abusivos os preços cobrados pela BR Distribuidora (Moura e Mendes, 2011). Entretanto, a eficácia da ação foi questionada, uma vez que a necessidade de se ter o combustível pode fazer com que o consumidor não leve em consideração as práticas abusivas de preço (mesmo que alertados por órgãos renomados, como o Ministério Público e Procon). A situação descrita anteriormente não pode ser considerada como uma postura socialmente responsável pela Petrobras e suas unidades de negócios, quando analisada na perspectiva da Teoria dos Stakeholders.

Estudos sobre comportamento do consumo em relação ao preço, por exemplo, mostram que a necessidade de um produto ou serviço é que define sua demanda (elástica ou inelástica). Conforme aponta a Teoria Econômica, os bens de luxo são preteridos em relação aos essenciais quando há uma redução da renda do consumidor - demanda elástica; e, os bens essenciais possuem uma demanda inelástica (Vasconcelos, 2001). Ou seja, a necessidade de um bem essencial é que define sua compra pelo consumidor - remédios têm demanda inelástica. Comparativamente, é possível que produtos ou serviços de luxo sejam preteridos pelos consumidores quando comparados aos bens essenciais, mesmo que estes últimos não sejam social ou ambientalmente corretos. Nesta lógica, bens como, combustível, transporte e alimentos não estariam propensos a sofrer boicotes por parte dos consumidores.

\section{PROPOSIÇÕES E SUGESTÕES PARA FUTURAS PESQUISAS NO BRASIL}

Um dos objetivos de um artigo exploratório, que tem como característica ser um texto qualitativo é apresentar insights ou proposições para novas pesquisas quantitativas e até mesmo qualitativas. A temática do boicote do consumidor na perspectiva da responsabilidade social é uma abordagem recente no contexto brasileiro, o que possibilita pensar diversos problemas de pesquisa na área. A primeira proposição que surge está relacionada à ideia central do artigo: a propensão do consumidor brasileiro participar de boicotes quando analisada a atuação da empresa no que diz respeito à responsabilidade social. Assim, tem-se:

\section{Proposição I}

O consumidor brasileiro está propenso a boicotar um produto ou serviço se ele tem a informação de que a empresa não é socialmente responsável.

Quando se considera a questão do ativismo, seja na questão ambiental ou social, o nível educacional dos ativistas é uma variável que deve ser considerada. Entende-se que quanto maior o nível educacional de um consumidor, maior será seu poder analítico e crítico. Talvez a profissão ou

Revista de Gestão Social e Ambiental - RGSA, São Paulo, v. 7, n. 1, p. 19-34, jan./abr. 2013. 
a área de atuação de um consumidor pode influenciar num boicote. Assim, se constrói a segunda proposição.

\section{Proposição II}

O nível educacional do consumidor pode influenciar no boicote por parte deste quando não for percebida uma postura socialmente responsável.

O consumidor que tem acesso às informações sobre a atuação de uma empresa e associa aos seus valores e naquilo que acredita ser o bom ou ruim, o certo ou errado, pode analisar se o comportamento de uma companhia fere seus princípios morais. A não congruência dos valores pessoais com o comportamento da empresa pode ajudar na decisão de boicotar, mas a necessidade do uso de um bem pode condicionar o seu comportamento. Assim, surgem as proposições III, IV e $\mathrm{V}$.

\section{Proposição III}

Recebendo a informação de que a empresa não é socialmente responsável, o consumidor brasileiro tende a boicotar bem de luxo quando comparado a um produto essencial.

\section{Proposição IV}

Bens essenciais, como combustível, alimentos e transporte, não estão propensos a serem boicotados por consumidores brasileiros.

\section{Proposição V}

Produtos ou serviços de empresas que atuam num mercado monopolista não receberão boicotes por parte dos consumidores pela impossibilidade de compra de outros concorrentes, mesmo que a empresa apresente fortes indícios de prejuízos à sociedade ou ao meio ambiente.

Conforme apontaram Klein, Smith e John (2004), o consumidor pode sofrer alguma pressão de familiares e amigos para participarem de um boicote ou então se acharem importantes ou não na participação de um boicote. Com base neste argumento e associando-a ao comportamento das empresas no que diz respeito à RSC, são sugeridas a sexta e sétima proposições.

\section{Proposição VI}

O posicionamento de pessoas que o consumidor consideram formadores de opinião (educadores, chefes, pais e amigos) influencia num boicote, casos estes o façam.

\section{Proposição VII}

O consumidor participará de um boicote mesmo que ele considere que sua participação seja pequena no universo que ele integra.

A questão da fidelidade de um consumidor a uma marca, produto ou serviço é outra questão que pode ser analisada quando se considera a questão do boicote. Intersubjetivamente na área de Marketing sabe-se que os consumidores estão dispostos a pagar mais ou se deslocarem para comprar produtos e serviços quando são fiéis a uma marca. É possível então que um consumidor fiel não boicote uma marca, conforme apresenta a oitava proposição.

\section{Proposição VIII}

Quanto mais fiel for um consumidor a um produto, maior será a dificuldade dele em boicotar a empresa que o produz, mesmo que esta tenha valores organizacionais diferentes dos seus valores pessoais. 
O custo de produção é um elemento-chave na estratégia de competitividade das empresas. Algumas vezes, utilizam-se estratégias eficientes para reduzir os custos de produção. Conforme aponta Smith et al. 2010, a Nike investe pesado em propaganda, mas repassa os custos de produção para a cadeia de produção e não arca com as consequências. Algumas empresas ainda não atendem a legislação vigente ou vão contra aos direitos humanos na relação com os seus colaboradores. Qual a percepção dos consumidores em relação a tais comportamentos? A Teoria Microeconômica aponta que o preço de um produto determina sua demanda de acordo com a renda do cliente. Será que o consumidor sensível ao preço poderá considerar práticas não legítimas na perspectiva dos direitos humanos e continua comprando produtos de uma empresa? A partir deste questionamento, surge a proposição IX.

\section{Proposição IX}

Se o preço de um produto ou serviço for inferior aos preços dos concorrentes, o consumidor sensível ao preço não considerará se a empresa é ou não socialmente responsável ao decidir pela compra do produto.

Estas e outras proposições podem contribuir no estudo do boicote, relacionando-a à RSC no contexto brasileiro. A discussão desta lacuna de conhecimento no contexto nacional que envolve estes três temas (responsabilidade social corporativa, boicotes e comportamento do consumidor), no contexto da Revista de Gestão Social e Ambiental, destaca quão presentes são estes temas no cotidiano das empresas e na tomada de novas atitudes dos consumidores em relação à RSC e ao boicote, possibilitando também em futuras pesquisas a análise deste contexto nas redes sociais virtuais. Ao apresentar proposições relacionadas à RSC na perspectiva do boicote do consumidor, diferenciando boicote de backlash, este estudo se torna pioneiro no país, tendo como legado uma discussão mais aprofundada na academia sobre questões relacionadas ao boicote dos consumidores no país.

\section{REFERÊNCIAS}

Aaker, D. J. (2004) Leaveraging the corporate brand. California Management Review. 46(3), 06-18. Agência Da Folha.(2007) Grupo Claudino determina boicote à Phillips no Piauí. Folha de São Paulo. Recuperado em: 13 mar. 2011, <http://www1.folha.uol.com.br/folha/brasil/ult96u321969.shtml>.

Argenti, P. A. (2005) Comunicação empresarial. Rio de Janeiro: Campus Elsevier.

Ashley, P.(2005) Ética e Responsabilidade Social nos Negócios. (2a . ed.) São Paulo: Saraiva.

Auperlle, K. E., Carroll, A. B. E Hatfield, J. D. (1985) An empirical examination of the relationship between corporate social responsibility and profitability. Academy Management Journal, 28(2)446463.

Barbosa, L.(2010) Consumo político: utopia ou realidade no Brasil? Recuperado em: 12 abr.2011, de: http:// colunistas.ig.com.br/consumoepropaganda/2010/11/16/consumo-politico-utopia-ourealidade-no-brasil/.

Bhattacharya, S. S., Sahay, A., Arora, A. P. E Chatuverdi, A.(2008) A toolkit for designing firm level strategic corporate social responsibility (CSR) initiatives. Social Responsibility Journal, 4(3), 265-282.

Crane, A., Mcwilliams, A., Matten, D., Moon, J. E Siegel, D.(2008) The Oxford Handbook of Corporate Social Responsibility. New York: The Oxford University Press.

Revista de Gestão Social e Ambiental - RGSA, São Paulo, v. 7, n. 1, p. 19-34, jan./abr. 2013. 
Cruz, B. de P. A. (2013) O boicote no comportamento do consumidor. Tese. Doutorado em Administração de Empresas, EAESP-FGV: São Paulo, 192 p.

(2012) The netnography in the consumers boycott studies: the Brazilian company Arezzo case. Revista de Administração do Gestor, 2, 119-146.

(2011) Boicote de consumidores: demarcação de conceitos e casos no Brasil. Anais do Enangrad, 17, São Paulo: ANGRAD.

(2009) Ensinando responsabilidade social para administradores: um enfoque gerencial contextualizado às características brasileiras. 3Es - ANPAD. Recife: ANPAD.

, Ross, S. D., Machado, J. J. B. E Abelha, D. M.(2012) Influência de Brasileiros Famosos no Boicote de Consumidores que Usam Redes Sociais Virtuais. Revista de Negócios, 17, 91-110.

e Ross, S. D.(2013) Percepção de culpa no boicote de um bem de luxo. Revista Pensamento Contemporâneo em Administração, 7, 139-155.

Curras-Perez, R., Bigne-Alcaniz, E., E Alvarado-Herreira, A.(2009) The role of self-definitional principles in consumer identification with a socially responsible company. Journal of Business Ethics, 89, 547-64.

Dahlsrud, A.(2008) How corporate social responsibility is defined: an analysis of 37 definitions. Corporate Social Responsibility and Environmental Management, 15, 1-13.

Donaldson, T., Preston, L. E. (1995) The stakeholder theory of corporation: concepts, evidence, and implications. Academy of Management Review, 20(1), 65-91.

Fitzsimons, G. J., Alba, J. W., Chartrand, T. I., Huber, J., Kardes, F. K., Menon, G., Raghubir, P., Russo, J. E., Shiv, B., E Tavassoli, N. T.(2002) Non-conscious influences on consumer choice. Marketing Letters, 13(3), 269-279.

Gardberg, N. A., Fombrum, C. J.(2006) Corporate citenzenship:creating intangible assets across institutional envirolments. Academy of Management Review, 31(2), 329-346.

Freeman, R. E. (1984) Strategic management: a stakeholder approach. Boston: Pitman. ., Velamuri, R.(2006) A new approach to CSR: company stakeholder responsibility. In: Reconciling aspirations with application. Basingstoke Palgrave Macmillan, 9-23.

Friedman, M.(1999) Consumer Boycotts - effecting change trough the marketplace and the media. New York: Routledge.Klein, J. G., Smith, N. C. E., John, A.(2004) Why we boycott: consumer motivations for boicott participation. Journal of Marketing, 68, 92-109.

Knight, R. F., Pretty, D. I.(2000) Brand risk management in a value context. Templeton Briefing. Oxford: Oxford University, 24-25.

Longman Dictionary.(2009) Longman Dictionary of Contemporary English. (5a. ed.) London: Longman Press.

Maignan, I., Ralston, D. A.(2002) Corporate social responsibility in Europe and the U.S.: insights from business' self-presentations. Journal of International Business Studies, 33(3), 497-514. 
Matilla, A. S., Hanks, L. E Kim, E. E. K.(2010) The impact of company type and corporate social responsibility messaging on consumer perceptions. Journal of Financial Services Marketing, 15(2), 126-135.

Melé, D.(2008) Corporate social responsibility theories. In: Crane, A., Mcwilliams, A., Matten, D., Moon, J., Siegel, D. The Oxford handbook of corporate social responsibility. New York: The Oxford University Press, 47-82.

Moura, R., Mendes, A.(2011) Órgãos de defesa do consumidor lançam campanha de boicote a postos BR. TV União. Recuperado em: 11 abr.2011, de: http://tvuniaodenatal.tv.br/noticia.php?id=1700.

Nan, X., Heo, K.(2007) Consumer responses to corporate social responsibility (CSR) Iniatives. The Journal of Advertising, 36(2), 63-74, Summer. Palazzo, G., Basu, K.(2007) The ethical backlash of corporate branding. Journal of Business Ethics, 73, 333-346.

Palazzo, G., Richter, U.(2005) CSR Business as Usual? The Case of the Tobacco Industry. Journal of Business Ethics, 33, 387-401.

Ramasamy, B., Yeung, M. C. H., e AU, A. K. M.(2010) Consumer support for corporate social responsibility (CSR): the role of religion and values. Journal of Bussiness Ethics, 91, 61-72.

Sindicato das Videolocadoras de São Paulo (2011) Sindicato das videolocadoras pede boicote ao filme Lula o Filho do Brasil. Recuperado em: 11 abr.2011, de: http://www.45graus.com.br/ sindicato-das-videolocadoras-pede-boicote-ao-filme-lula-o-filho-do-brasil,geral,59820.html .

Soule, S. A.(2009) Contention and corporate social responsibility. Oxford: Cambridge University Press.

Smith, N. C., Palazzo, G., E Bhattacharya, C. B.(2010) Marketing consequences: stakeholder marketing and supply chain corporate social responsibility issues. Business Ethics Quartely, 617641 , oct .

Tenório, F.G. (Org).(2004) Responsabilidade social empresarial: teoria e prática. Coleção FGV Prática. Rio de Janeiro: Editora FGV.

Vasconcelos, M. A. S. de.(2001) Economia - Micro e macro. São Paulo: Editora Atlas.

Wood, T.(1991) Corporate social performance reviseted. Academy of Management Review, 16, 691718.

i. MELÉ, D. Corporate Social Responsibility Theories. In: Crane, A., Mcwilliams, A., Matten, D., Moon, J. e SIEGEL, D. The Oxford Handbook of Corporate Social Responsibility. New York: The Oxford University Press, 2008, p. 47-82.

ii. Uma análise aprofundada sobre a Teoria do Stakeholders pode ser conduzida a partir dos trabalhos de Freeman (1984) e Freeman e Velamuri (2006).

iii. Os autores citados aqui são encontrados no texto de Currás-Pérez et al (2009).

Data da submissão: 30/09/2011

Data da publicação: 30/04/2013 